\title{
Biochemical basis of resistance in wheat against Karnal bunt caused by Tilletia indica
}

\author{
MANINDERJEET SINGH ${ }^{1}$, RITU BALA ${ }^{2 *}$, VINEET K. SHARMA ${ }^{1}$, JASPAL KAUR ${ }^{2}$ and SUCHETA SHARMA ${ }^{3}$ \\ ${ }^{1}$ Department of Plant Pathology, ${ }^{2}$ Department of Plant Breeding and Genetics, ${ }^{3}$ Department of Biochemistry, Punjab Agricultural \\ University, Ludhiana 141 004, Punjab, India
}

Received: 22 April 2017/ Accepted: 24 May 2017/ Published online: 25 May 2017

(C) Indian Phytopathological Society 2017

\begin{abstract}
The biochemical basis of Karnal bunt resistance was evaluated in four resistant (ALDAN, CMH77.308, H567.71 and HP1531) and two susceptible (PBW343 and HD2967) genotypes. The parameters studied included total phenols and defense related enzymes (peroxidase, phenylalanine ammonia lyase and polyphenol oxidase). The level of total phenols and activity of the defense related enzymes was more in resistant as compared to the susceptible genotypes. However, there was variation within the resistant genotypes. Maximum level of total phenols was observed in CMH77.308 at 3 days after inoculation while maximum peroxidase activity was observed in $\mathrm{H} 567.71$ after 2 days of inoculation. The activity of polyphenol oxidase was highest after 3 days of inoculation in the resistant genotype HP1531 while maximum activity of phenylalanine ammonia lyase was observed in H567.71 after 3 days of inoculation.
\end{abstract}

Keywords: Karnal bunt, peroxidase, phenylalanine ammonia lyase, polyphenol oxidase, Tilletia indica, total phenols, wheat

Karnal bunt (KB) or partial bunt of wheat incited by Tilletia indica has been reported from several wheat growing countries of the world including India (Rush et al., 2005). Due to its partial nature, yield losses are few but quality is a serious issue with the import of $\mathrm{KB}$ infected grains. The quarantine regulations or zero tolerance by many countries makes it a serious non-tariff barrier to international trade.

Being a seed, soil and air-borne disease, it is difficult to manage it. There are conventional approaches such as crop rotation, sowing of disease free seeds and adjustment of the time of irrigation to minimize KB infection (Singh, 1985). Similarly, chemical control of the disease is very much effective but is neither eco-friendly nor cost effective (Singh et al., 1985). Deployment of host plant resistance is the most effective and economical method for KB management but it is a tedious task owing to labour intensive screening procedures. Nevertheless, differential resistance at biochemical level would help to understand nature of Karnal bunt resistance and its further exploitation for effective disease control. Several attempts have been made to know the basis of biochemical resistance of wheat diseases (Johnson and Lee, 1978; Moerschbacher et al., 1989; Patykowski et al., 1988; Rengel et al., 1994). However, very few workers have reported this aspect with respect to KB ( $T$. indica) wheat host pathogen interactions. Therefore, the present study was planned to elucidate the biochemical basis of resistance in KB resistant and susceptible genotypes.

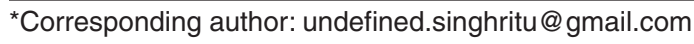

\section{MATERIALS AND METHODS}

Material

The present investigation was conducted in the experimental fields and laboratories of Department of Plant Breeding \& Genetics and Department of Biochemistry, Punjab Agricultural University, Ludhiana during the period 2013-2015. Sowing of four Karnal bunt resistant (ALDAN, HP 1531, CMH 77.308 and H567.71) and two susceptible (HD 2967 and PBW 343) wheat genotypes was done in the last week of November. Sowing was done at a spacing of $22.5 \mathrm{~cm}$ in $2 \times 2 \mathrm{~m}^{2}$ beds. After sowing of wheat, all the cultural operations were done according to the standard practices (Anonymous, 2014).

\section{Pathogen isolation, multiplication and maintenance}

Twenty isolates of $T$. indica were collected from all over the Punjab. Isolation, purification, mass multiplication and maintenance of all the isolates were done on Potato Dextrose Agar (PDA) medium. Inoculum was prepared by mixing all the available isolates in equal proportions. For preparing the inoculum suspension, sterilized distilled water was added to the test tubes and with the help of glass rod, the fungal sporidia were gently scrapped to remove allantiod secondary sporidia. Inoculum suspension was then filtered through double layer of muslin cloth and its concentration was adjusted at more than 10,000 sporidia per $\mathrm{ml}$. 
Table 1. Total phenolic content in resistant and susceptible wheat genotypes after inoculation with $T$. indica

\begin{tabular}{lcccccc}
\hline Genotype & \multicolumn{9}{c}{ Total phenolic content $\left(\mathrm{mg} \mathrm{g}^{-1}\right.$ dry weight) after days } \\
\cline { 2 - 7 } & 0 & 1 & 2 & 3 & 4 & 3 \\
\hline ALDAN & 18.80 & 37.27 & 43.60 & 50.07 & 36.03 & 31.37 \\
CMH77.308 & 26.90 & 37.43 & 48.00 & 78.83 & 57.09 & 33.90 \\
H567.71 & 25.73 & 43.50 & 45.40 & 53.47 & 38.77 & 24.33 \\
HP1531 & 22.17 & 45.77 & 55.80 & 68.07 & 48.80 & 27.97 \\
HD2967 & 12.57 & 18.13 & 21.46 & 24.60 & 15.93 & 14.93 \\
PBW343 & 11.33 & 16.03 & 26.10 & 19.57 & 16.23 & 13.47 \\
\hline
\end{tabular}

$C D(p=0.05) \quad$ Genotype $(A)=1.87$, Days after inoculation $(B)=1.87, A \times B=4.57$

\section{Artificial inoculation of the genotypes and collection of samples}

In each of the six parents, 25 plants were inoculated at boot leaf stage by syringe inoculation method (Aujla et al., 1982). The inoculated ears were used for estimation of defense related enzymes after one day interval till five days of inoculation.

\section{Biochemical analysis}

Estimation of total phenols, peroxidase (POD), polyphenol oxidase (PPO) and phenylalanine ammonia lyase (PAL) was done by following standard methods given by Swain and Hills (1959), Shannon et al. (1996), Zauberman et al. (1991) and Burrell and Rees (1974), respectively.

\section{RESULTS AND DISCUSSION}

The results obtained in the present study with respect to total phenols and defense related enzymes against $T$. indica, the causal agent of Karnal bunt are presented and interpreted individually as follows:

\section{Total phenolic content}

An increase in total phenolic content after inoculation was noticed in all the wheat genotypes. This was followed by a decrease after the peak concentration. The peak concentration in all the genotypes was achieved after 3 days of inoculation (DAI) except PBW 343 which had the maximum level of total phenols after $2 \mathrm{DAI}$. A perusal of the data presented in Table 1 showed that among the resistant genotypes, total phenol content was maximum (78.8 $\mathrm{mg} \mathrm{g}^{-1}$ dry weight) in $\mathrm{CMH77.308}$ at 3 DAl followed by HP1531 (68.07 $\mathrm{mg} \mathrm{g}^{-1}$ dry weight), H567.71 (53.47 $\mathrm{mg} \mathrm{g}^{-1}$ dry weight) and ALDAN (50.07 $\mathrm{mg} \mathrm{g}^{-1}$ dry weight). PBW343 and HD2967, being the susceptible checks exhibited lower phenolic content (26.10, 2DAl and 24.60, 3DAl $\mathrm{mg} \mathrm{g}^{-1}$ dry weight, respectively) as compared to resistant genotypes.

\section{Activity of defense related enzymes}

Peroxidase activity: Four genotypes viz., ALDAN, $\mathrm{CMH}$ 77.308, HP 1531 and HD 2967 exhibited maximum peroxidase activity $3 \mathrm{DAl}$ whereas it was $2 \mathrm{DAl}$ in $\mathrm{H}$ 567.71 and PBW 343 (Table 2). The level of peroxidase (POD) activity was statistically at par in H567.71 (178.1 units $\mathrm{min}^{-1} \mathrm{~g}^{-1}$ fresh weight, 2DAI), and $\mathrm{CMH} 77.308$ (176.8 units $\mathrm{min}^{-1} \mathrm{~g}^{-1}$ fresh weight, 3DAI) irrespective of DAI with $T$. indica. In HP 1531, the level of POD activity (174.8 units $\mathrm{min}^{-1} \mathrm{~g}^{-1}$ fresh weight,3DAl) was at par with $\mathrm{CMH} 77.308$ but it was different from H567.71. In susceptible genotypes, the increase was significantly less than resistant ones.

Polyphenol oxidase activity: A noticeable difference was observed in polyphenol oxidase (PPO) activity in the resistant as compared to the susceptible genotypes of wheat to T. indica (Table 2).

Considering all the genotypes, peak activity of the enzyme was observed 3 DAl except PBW 343 which revealed maximum $\mathrm{PPO}$ activity 2 days after inoculation. Among the resistant genotypes, maximum PPO activity was observed after 3 DAl in HP 1531 (21.6 units min $^{-1}$ $\mathrm{g}^{-1}$ fresh weight) and H567.71 (19.4 units min $^{-1} \mathrm{~g}^{-1}$ fresh weight), and it was minimum in ALDAN (14.3 units min $^{-1}$ $\mathrm{g}^{-1}$ fresh weight). Among the susceptible genotypes, HD 2967 had more level of PPO (10.4 units min $^{-1} \mathrm{~g}^{-1}$ fresh weight) as compared to PBW 343 (9.7 units min $^{-1} \mathrm{~g}^{-1}$ fresh weight, $2 \mathrm{DAI})$. The results revealed that resistant genotypes showed significantly more level of PPO as compared to the susceptible genotypes.

Phenylalanine ammonia lyase activity: A perusal of the data presented in Table 2 indicated that among the resistant genotypes, $\mathrm{H} 567.71$ (1098.2 $\mu \mathrm{g}$ t cinnamic acid formed $\mathrm{hr}^{-1} \mathrm{~g}^{-1}$ fresh weight) and $\mathrm{CMH77.308} \mathrm{(1037.2} \mu \mathrm{g}$ $\mathrm{t}$-cinnamic acid formed $\mathrm{hr}^{-1} \mathrm{~g}^{-1}$ fresh weight) showed maximum phenylalanine ammonia lyase (PAL) activity after 3 DAI, while minimum PAL activity $(917.1 \mu \mathrm{g} \mathrm{t}-$ cinnamic acid formed $\mathrm{hr}^{-1} \mathrm{~g}^{-1}$ fresh weight, 4DAl) was observed in HP1531. Among susceptible genotypes, HD2967 (564.4 $\mu \mathrm{g}$ t-cinnamic acid formed $\mathrm{hr}^{-1} \mathrm{~g}^{-1}$ fresh weight, $4 \mathrm{DAl}$ ) exhibited more PAL activity as compared to PBW 343 (511.9 $\mu \mathrm{g} \mathrm{t}$-cinnamic acid formed $\mathrm{hr}^{-1} \mathrm{~g}^{-1}$ fresh weight, $4 \mathrm{DAI})$. PAL activity was significantly more in the resistant as compared to the susceptible genotypes. Peak activity of the enzyme was observed at 3 DAl in two genotypes (CMH 77.308, H567.71) and after $4 \mathrm{DAl}$ in remaining four other genotypes (ALDAN, HP 1531, HD2967, PBW 343). 
The data presented in both the tables (Table 1, 2) showed an increase in the total phenolic acids as well as defense related enzymes viz., POD, PPO and PAL after inoculation with $T$. indica irrespective of the genotypes. However, the level of increase in resistant genotypes was significantly higher than the susceptible ones suggesting a role of these chemicals in resistance against T. indica.

Among the resistant genotypes, maximum total phenols were exhibited by $\mathrm{CMH77.308}$. The POD and PAL activity was maximum in H567.71. Likewise, HP1531 had maximum PPO activity after inoculation with the test pathogen. This difference in level of production of theses defense related chemicals may be attributed to the genetic potential of the genotypes. However, both the susceptible genotypes were statistically different from each other with respect to production of phenols and defense related enzymes, however, the difference was small.

The results obtained in the present study can be corroborated with the earlier findings. Gill et al. (1993) correlated phenol status of wheat with KB resistance. Similarly, Bakhshi et al. (1989) reported that the increase in the phenolics in the KB resistant genotypes could be due to the activities of enzymes such as polyphenol oxidase and peroxidase during host pathogen interactions.

Furthermore, Gogoi et al. (2001) have also described role of phenols and peroxidase in imparting resistance to wheat against Karnal bunt of wheat. According to them, phenols were induced in the both resistant and susceptible genotypes of wheat after inoculation with $T$. indica, but were synthesized at higher than normal levels in the resistant as compared to the susceptible genotypes only during the early stages of infection by the pathogen, being enhanced upto 6 days in the resistant genotype DWL 5023.

Purwar et al. (2012) while investigating the role of defense related enzymes in imparting resistance against Karnal bunt of wheat reported that PAL and PPO activity was significantly higher in all the developmental stages of resistant genotype (HD 29) than the susceptible genotype (WH 542).

Disease resistance in plants is associated with activation of a wide array of defense responses that slow down or halt infection at certain stages of the host pathogen interactions and total phenols and defense related chemicals impart resistance against a pathogen. The present study indicated the possible role of the total phenols and defense related enzymes in imparting resistance against the $T$. indica in wheat.

\section{REFERENCES}

Anonymous (2014). Package of practices for rabi crops. pp 118. Punjab Agricultural University, Ludhiana.

Aujla SS, Grewal AS, Gill KS and Sharma I (1982). Artificial creation of Karnal bunt disease of wheat. Cereal Res. Commun. 10: 171-176. 
Bakhshi AK, Saxena AK, Sharma AK, Sharma I, Aujla SS and Singh B (1989). Biochemical changes in host-pathogen interaction in Karnal bunt infected wheat. Indian J. Plant Pathol. 7: 32-35.

Burrell MM and Rees TAP (1974). Metabolism of phenylalanine and tyrosine in rice leaves infected by Pyricularia oryzae. Physiol. Pl. Pathol 4: 497-508.

Gill KS, Sharma I and Aujla SS (1993). Karnal Bunt and Wheat Production. Punjab Agricultural University, Ludhiana, India.

Gogoi R, Singh DV and Srivastava KD (2001) Phenols as a biochemical basis of resistance in wheat against Karnal bunt. PI. Pathol. 50: 470-476.

Johnson LB and Lee RF (1978). Peroxidase changes in wheat isolines with compatible and incompatible leaf rust infections. Physiol. Plant Path. 13: 173-181.

Moerschbacher BM, Flott BE, Noll U and Reisiner HJ (1989). On the specificity of an elicitor preparation from stem rust which induces lignification in wheat leaves. Plant Physiol. Biochem. 27: 305-314.

Patykowski J, Urbanek H and Kaczorowska T (1988). Peroxidase activity in leaves of wheat cultivars differing in resistance to Erysiphe graminis DC. J. Phytopathol. 122: 126-134.

Purwar S, Gupta SM and Kumar A (2012). Enzymes of phenylpropanoid metabolism involved in strengthening the structural barrier for providing genotype and stage dependent resistance to Karnal bunt in wheat. Am. J. Pl. Sci. 3: 261-267.

Rengel D, Graham R and Pedler J (1994). Time course of biosynthesis of phenolics and lignin in roots of wheat genotypes differing in manganese efficiency and resistance to take-all fungus. Ann. Bot. 74: 471477.

Rush CM, Stein JM, Bowden RL, Riemenschneider R, Boratynski T and Royer MH (2005). Status of Karnal bunt of wheat in the United States 1996-2004. Plant Dis. 89: 212-223.

Shannon LM, Kay E and Lew JY (1996). Peroxidase isozymes from horseradish roots.I. Isolation and physical properties. J. Biol. Chem. 241: 2166-2172.

Singh DV, Srivastava KD, Joshi CM and Verma BR (1985). Evaluation of some fungicides for the control of the Karnal bunt of wheat. Indian Phytopath. 38: 571-573.

Singh SL (1985). Cultural practices and the Karnal bunt incidence. Indian Phytopath. 38: 594.

Swain T and Hills WE (1959). The phenolic constituents of Prunus domestica-the qualitative analysis of phenolic constituents. J. Sci. Fd. Agric. 10: 63-68.

Zauberman G, Ronen R, Akerman M, Weksler A, Rot I and Fuchs $Y$ (1991). Postharvest retention of the red color of litchi fruit pericarp. Sci. Hort. 47: 89-97. 